\title{
Stability and change in fertility intentions in Britain, 1991-2007
}

\author{
Máire Ní Bhrolcháin, Eva Beaujouan, Ann Berrington
}

University of Southampton

\begin{abstract}
The very low fertility experienced in several European countries in recent decades in the presence of higher intended family sizes has renewed interest in fertility intentions data. While the overall level of childbearing in Britain over the past few decades has remained relatively stable and high in comparison with many other European countries, we have seen sizeable increases in the age at which childbearing starts. This study uses data from the 1991 to 2007 General Household Surveys to examine trends in family intentions data in an attempt to arrive at a better understanding of these recent fertility developments. First, time trends in intended family size are compared with trends in observed fertility. Next, aggregate changes in intentions regarding the level and timing of fertility across the life course for cohorts are investigated together with the extent to which these aggregate intentions are matched by the subsequent childbearing of cohorts. Finally, both change across the life course and uncertainty in family intentions are examined. We conclude by discussing what these findings might tell us about contemporary reproductive decision making.
\end{abstract}




\section{Contents}

Stability and change in fertility intentions in Britain, 1991-2007 .13

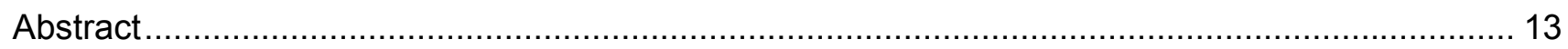

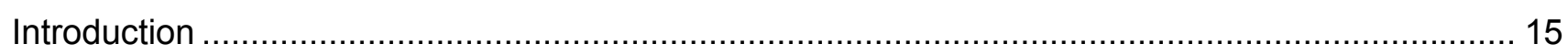

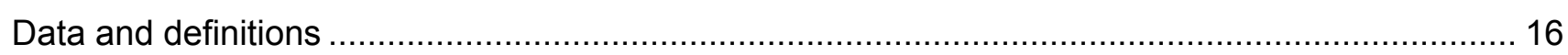

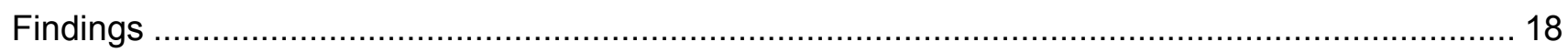

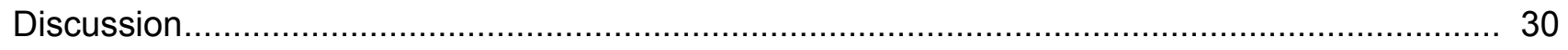

Acknowledgements

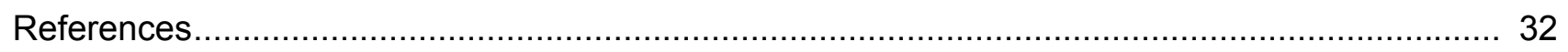




\section{Introduction}

Fertility in Britain in the last decades has displayed both stability and change. Stability is seen in the narrow range of 1.62 to 1.95 within which the total fertility rate (TFR) -an annual summary indicator of hypothetical family size if current birth rates were to persist- has been fluctuating since the early 1970s. Substantial change has been occurring, on the other hand, in the timetable of family formation. For three decades, women have been having children at progressively older ages than customary in the recent past with the result that the age-standardised mean age at childbearing is, at 29.3 years, now higher than at any time since 1938, when records of age at birth first became available in vital statistics. Britain's combination of several decades of relatively stable, low fertility with a strong trend to later childbearing is shared with other countries of northern and western Europe ${ }^{1}$. But, along with France and some Scandinavian countries, it has maintained a level of fertility well above that of some central and southern European countries. For example, around 2006, the TFR in countries of western and northern Europe (excluding the Germanspeaking countries) was between 1.7 and 2.0, while most other regions of Europe displayed TFRs below 1.5. Almost all European countries have seen a rapid increase in the age at first birth, but inter-country differences remain. For example, in 2006, mean age at first birth in Spain was around 29 years, while in Russia childbearing was much earlier, with an average age at first birth of 24 years $^{2}$.

While the overall level of fertility in Britain has, in recent decades, been relatively stable, there have nevertheless been some short to medium-term trends. During the 1990s the TFR declined steadily from 1.84 in 1991, reaching a low of 1.62 in 2001. The TFR then turned up over several years, reaching 1.95 in 2008, an increase of 0.33 births per woman (20 per cent) over 2001. Most (69 per cent) of the rise of 0.33 children per woman from 2001-2008 was due to rising birth rates of women aged 30 and over, continuing a trend in place since the late 1970s. A further 25 per cent is due to women aged 25-29, reflecting a slight turnaround in the birth propensity at this age. Women in their early twenties account for a small part of the increase, with little indication as yet of a move away from the relatively low rates reached at these younger ages. Rising fertility has also been observed in the new millennium in several other European countries, the causes of which are yet to be established $^{3}$. Suggested explanations include an end to the move to later childbearing, economic growth, pronatalist and other family policies, and higher immigrant fertility. Recent research on the role of migrant childbearing in the UK shows that, while the overall proportion of births to foreign born women has increased significantly, the rise in the overall UK TFR is mainly due to increases in the fertility of UK-born women ${ }^{4}$.

The present study examines time trends in family intentions data in an attempt to arrive at a better understanding of recent trends. Fertility intentions data have long been studied in demography and can be deployed in several ways. Early investigators had recourse to such data as an input to population projection assumptions. But optimism in that respect gave way to considerable scepticism, with the accumulation of evidence that aggregate fertility intentions tend to reflect current conditions rather than future prospects ${ }^{5} 67$. The very low fertility experienced in several European countries in recent decades has renewed interest in intentions data, as mean intended or desired family size has been found to be above period estimates of family size ${ }^{8}$. This has been interpreted in several ways. The difference between the current TFR and desired family size is seen by some as signalling a likely future upturn of period fertility levels to reach expressed preferences, by others as reflecting the opposite- that declared intentions will ultimately decline to 
reflect current actual fertility levels-and alternatively as reflecting a disjunction that could continue indefinitely in low fertility societies ${ }^{9}$. The apparent shortfall of actual compared with desired fertility has also been viewed as resulting from barriers to the achievement of desired family size, and thus as the rationale for family-friendly policy intervention ${ }^{10}$. This latter perspective has prompted several cross-national investigations of fertility intentions in a European context ${ }^{11}$.

Beyond issues of future prospects and policy, fertility intentions may contribute to enhancing understanding and interpretation of recent trends in fertility ${ }^{9}$ and that is the purpose of the present study. The shift in the timetable of childbearing in recent decades has been substantial but remains to be fully documented and explained. The phenomenon is widely referred to as postponement though doubts have been expressed as to whether that term is either accurate or useful as a description of the underlying behaviour giving rise to changing tempo ${ }^{12}$. In this article, we look to fertility intentions data from the General Household Survey, in an attempt to clarify recent change in family building patterns, updating a previous analysis of the same data to $2002^{13}$. Our study has four components. We start by looking at time trends in fertility intentions and then assess the accuracy of childless women's fertility intentions in the aggregate. We go on to consider the variation in fertility intentions across the life-course, and finally examine the extent and patterns of uncertainty expressed in answer to questions on fertility intentions. We conclude with some reflections on what these data suggest about the process of reproductive decision making.

\section{Data and definitions}

\section{Data}

The data used are from a combined file GHS dataset for the period 1991-2007. Only female respondents are asked to report a fertility history and also to provide information about their intended fertility; and so the present analysis is confined to women.

During the earlier part of the period covered by the present study, GHS fieldwork was on a financial year basis. Hence what we refer to as the $1991 \mathrm{GHS}$ round took place between April 1991 and March 1992. In 2005, the survey reverted to a calendar year basis ${ }^{14}$. In a further change, a longitudinal structure was initiated in 2005. As a result, three quarters of households and persons interviewed in 2006 and 2007 were re-interviews. Repeat interviews in 2006 and 2007 are omitted from the present analysis, and as sample numbers are therefore small in 2006 and 2007, the years 2005-07 are combined in all calendar year analyses. The tables and analyses presented here are weighted for the years 1996 to 2007 when survey weights were available for the GHS. Weights have been scaled by the average weight for the year in question.

Official statistics on aggregate fertility trends are generally published separately for England and Wales and for Scotland. However, the GHS covers the population of Great Britain (England, Wales and Scotland). When referring to national statistics not available for GB, we cite England and Wales figures and indicate this in the text. In general, any discrepancy with the true GB figure will not be substantial.

\section{Measures of intentions}

Several measures of intentions are used in the present article: whether a (further) birth is intended, intended family size, and, among those intending a (further) birth, the expected age at next birth. 
The question wording and sequence is given in Box one. The question on intention regarding a (further) birth combined with a probe for "don't knows", has the categories: "yes", "probably yes". "no", "probably no", and "don't know".

Intended family size is measured as follows: (a) the stated intended family size of women answering "yes" or "probably yes" to the question on whether they expected to have any (more) children; in the small proportion of cases where the woman had already had more than the recorded intended number, her actual parity was used; (b) where women answered "no", "probably no" or "don't know" to the intentions questions, the number of births that respondents had already had, augmented by one if the woman was pregnant at interview. The latter addition was for consistency with those answering "yes" or "probably yes", who were asked to include the baby they were expecting in their stated intended family size.

\section{Box one Fertility intentions questions asked of women aged 16-49 years in the GHS from 1991 onwards}

\section{Ask all women aged 16 to 49}

Do you think that you will have any (more) children (after the one you are expecting)? Could you choose your answers from this card.

Yes. 1

Probably yes.

Probably not

No

Don't know......

\section{Ask if respondent answered don't know above}

On the whole do you think...

You will probably have any/more children

Or you will probably not have any/more children?

\section{Ask if respondent is likely to have more children}

How many children do you think you will have born to you in total, including those you have had already who are still alive/ (and) the one you are expecting?

How old do you think you will be when you have your first/next baby (after the one you are expecting)? 
Women answering "yes" or "probably yes" to the question on whether they expected to have a (further) birth were asked to state the age at which they expected to have that birth. The expected time to (next) birth is measured as the difference between this age and the respondent's age at interview.

As Smallwood and Jefferies ${ }^{13}$ noted, the GHS questions on fertility intentions are worded so as to elicit realistic answers on their fertility expectations, rather than ideals or desires. With previous authors, we regard intentions and expectations in this area as synonymous.

\section{Time period}

To ensure comparability across time, the analysis is confined to intentions data for the period 1991 onwards. Between 1979 and 1990, a sizeable minority of women (nine per cent to 13 per cent) answered "don't know" to the fertility intentions question. The question format changed in 1991 with the addition of "probably yes" and "probably no" categories, thus reducing the number of "don't knows". Also, a question was added to probe "don't know" answers further (see Smallwood and Jefferies 2003, Annex A) ${ }^{13}$. The additional question results in a re-classification of 71 per cent of the original three per cent of "don't know" answers to "probably yes" (40 per cent) or "probably no" (31 per cent), thus reducing non-statement to under one per cent of the total.

\section{Parity}

Parity, the number of births a woman has had, should ideally be based on the declared number of live births reported in the Family Information section of the GHS. However, a recent study has identified deficiencies in the GHS fertility histories. Murphy (2009) shows that when followed from one GHS round to later rounds, several older birth cohorts record an (intra-cohort) increase in childlessness. For example, 12.8 per cent of women born in 1950-54 were childless at age 40-44, but this figure had risen to 20.7 per cent of the same cohort at ages $55-59^{15}$. Further analysis has revealed, however, that sizeable proportions of women who were declared childless according to the Family Information section of the survey had reported children of their own living in the household, particularly from the GHS round 2000-01 onward ${ }^{16}$. A revised birth history was therefore constructed by combining the live births declared in the Family Information section of the questionnaire with the birth dates of own children in the household, for the period 1994 on. These revised fertility histories are used in the present article both to define parity at survey and as an estimate of the intended family size of women not expecting any further birth. They are, however, provisional in that a full assessment of the original errors in the fertility histories, and of the accuracy of the reconstruction, remains to be finalised.

\section{Findings}

\section{Time trends in intentions}

We consider in this section whether and how time-trends in stated intentions are associated with fertility trends. Do intentions data help in anticipating future childbearing trends, or in interpreting recent developments?

On the question of anticipation, the answer is negative. Average intentions in the GHS gave no early warning of the upturn in fertility from 2001 onwards. An intended period mean family size analogous to the period TFR - the unweighted average mean intended family size across single 
years of age 16-39 in each year - is shown in Figure 1 for the period 1991-2005/07, together with the TFR (England and Wales) for the same period (for comparability with vital registration statistics, the intentions data are plotted against year of interview rather than survey year). Mean intended family size ranges between 2.0 to 2.16 children per woman over this 17 year period. Throughout the period it is well above the observed TFR by between 0.3 and 0.4 children per woman to 2001 , with the gap narrowing somewhat thereafter. Mean intended family size declines along with the TFR from 1991 on, but what evidence there is of an upturn in aggregate intentions is simultaneous with, rather than predating, the change point in total fertility. Furthermore, the change from 2001$2005 / 07$ in mean intended family size of 0.07 children per woman was just a quarter of the change in total fertility between those dates. These findings are in accord with long-standing evidence that, in the aggregate, fertility intentions tend either to coincide with or to lag, rather than to lead, period trends in fertility ${ }^{5}$.

\section{Figure 1 Mean intended family size and total fertility rate, Great Britain 1991-2007}

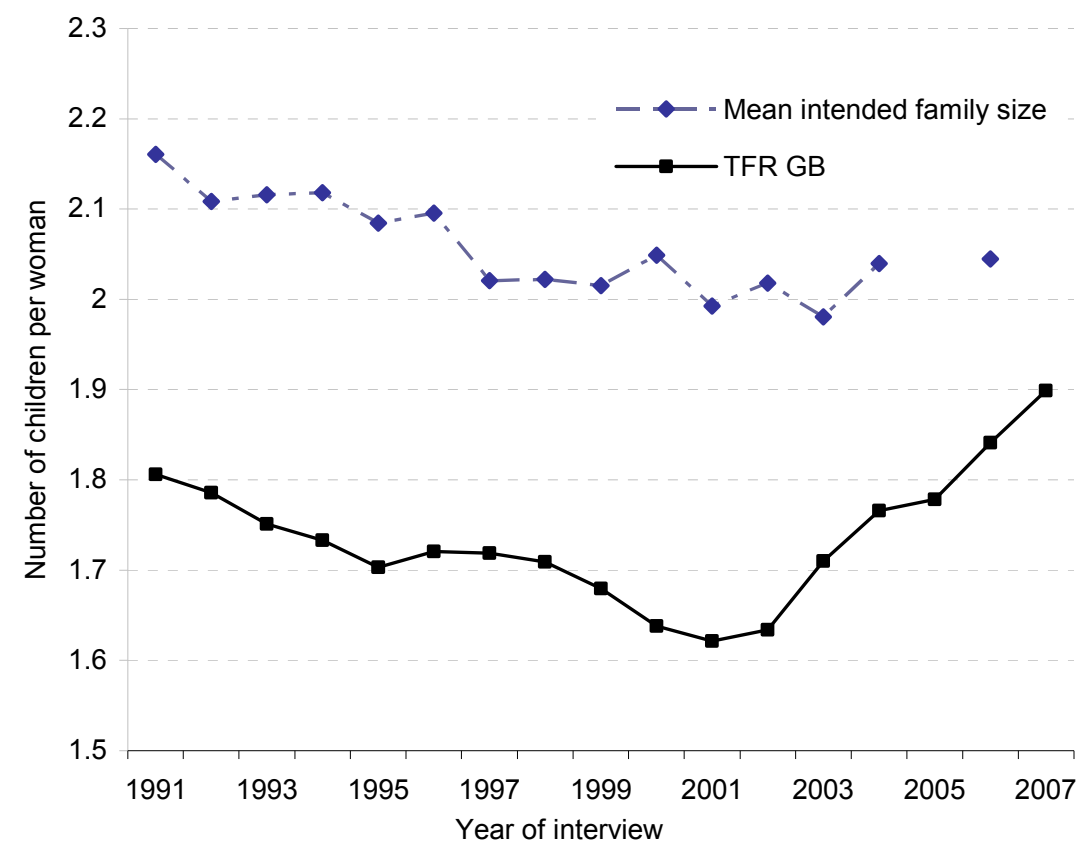

Sample: mean intentions based on women aged 16-39.

For comparability with vital registration statistics, the intentions data are plotted against year of interview rather than survey year; for consistency, the combined years 2005-07 are plotted against 2006.

Source: CPC GHS time series datafile

The correspondence between trends in intentions and in aggregate fertility is, however, confined to very broad aggregate measures. The picture alters when we examine a more specific measure of intentions, that is, whether a woman expects to have a (further) birth. This type of question is seen by several investigators as more concrete and immediate, and having a sounder evidential base in relation to validity and reliability, than ultimate intended family size ${ }^{17}$. Furthermore it fits well with established demographic evidence that fertility decisions in low fertility societies are specific by parity, family building decisions being taken one at a time. Unlike average intentions, this 
alternative indicator did not, in general, follow the TFR's decline and recovery during the period 1991-2007. Also, trends in the intention to have at least one more child differ somewhat between childless women and those who are already mothers. This is seen in Figure $\mathbf{2 a}$ and $\mathbf{2} \mathbf{b}$, which show trends in the proportion saying "yes" to the question on whether the respondent expects to have a (further) birth. From the mid 1990s, the proportion intending at least one further birth shifts upward among childless women in their mid-20s and above ${ }^{18}$. Among women with children, the intention to have a further birth initially declines among younger women, and is constant in older groups, before rising in all groups later in the period. Note that Figures 2a, b give the proportions stating a definite intention to have a birth but that, as we will see later, a substantial minority also express uncertainty about future childbearing. Hence, the complement of the proportions plotted in these diagrams is not the proportion stating that they do not wish to have a (further) birth. In fact, the proportion stating that they do not intend a (further) birth among both childless women and those with children drifts down over the period in all but the youngest age groups, as is seen in Figure $3 a$ and $3 b$.

\section{Figure 2 Percentage intending to have a (further) child by age at survey and year, Great Britain, 1991/92-2005/07}

a) childless women

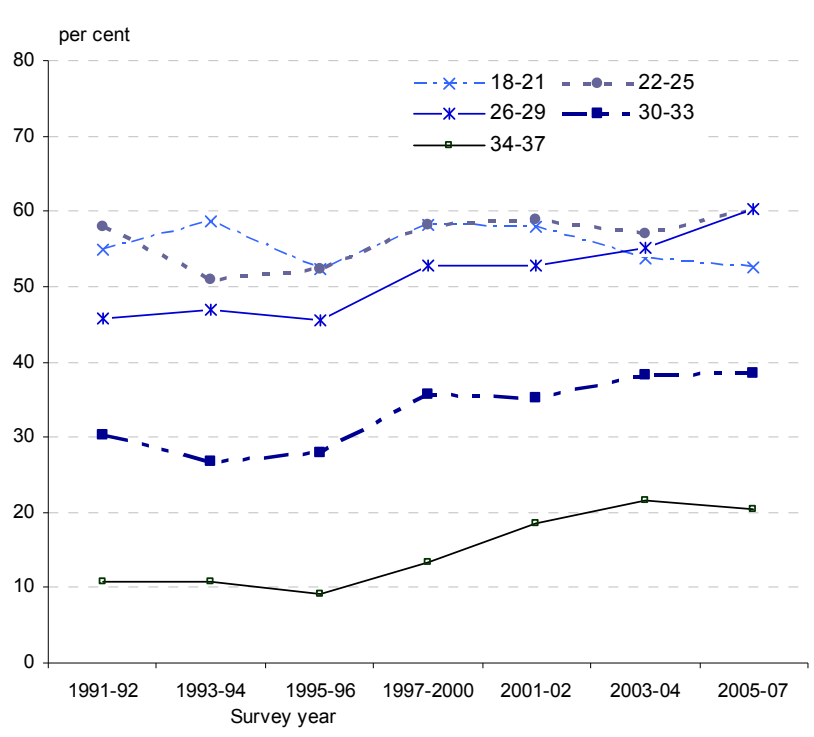

b) women of parity $1+$

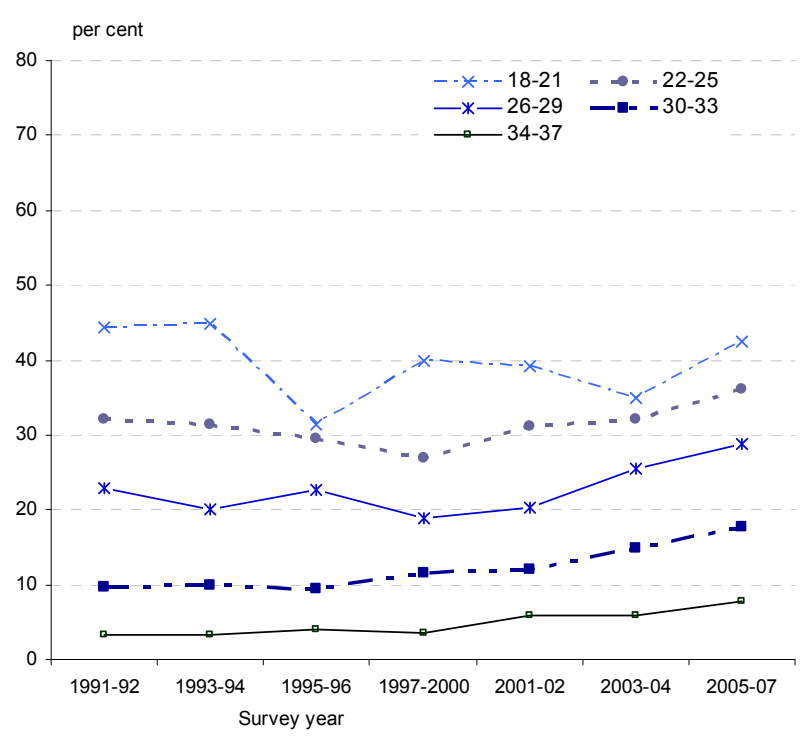

Note: proportions answering "yes" to the first question in Box one.

Source: CPC GHS time series datafile

These findings have implications for the interpretation both of fertility trends and of information on intentions. A process of delaying first birth has, in general, been inferred from time trends in age specific rates and from the rise in the mean age at first birth. That inference goes beyond the evidence, however, in that the move to later childbearing could result from several underlying processes $^{12}$. The intentions data provide direct contemporaneous evidence that confirms recent fertility trends as a process of progressive delay, rather than for example, that the declining rates at younger ages reflected initial decisions against childbearing that were subsequently reversed at later ages. 


\section{Figure 3 Percentage intending not to have a (further) child by age at survey and year, Great Britain, 1991/92-2005/07}

a) childless women

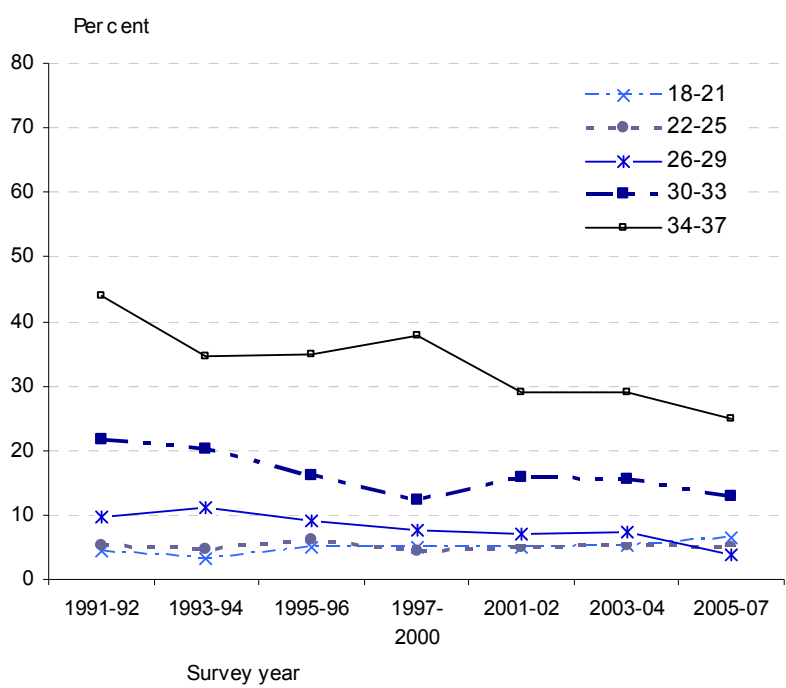

b) women of parity $1+$

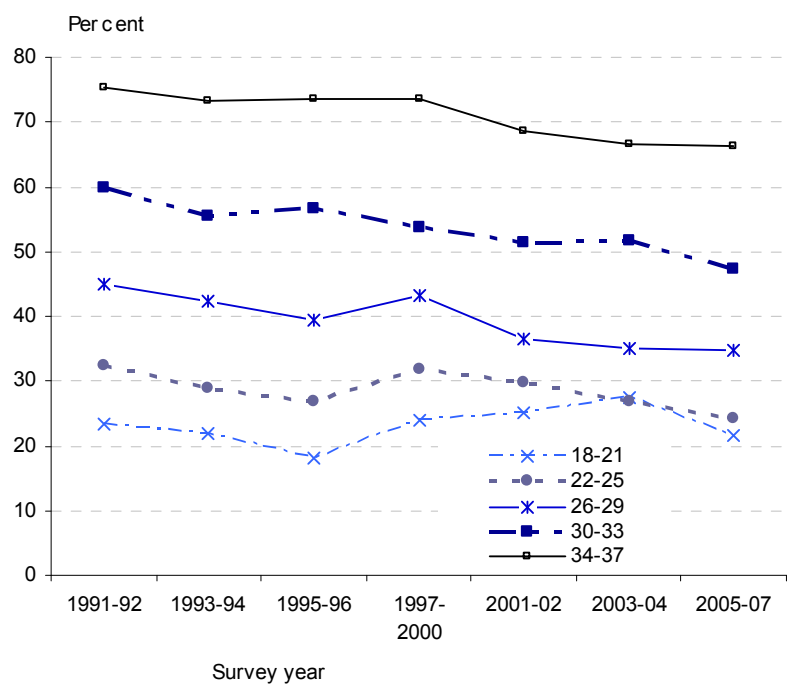

Note: proportions answering "no" to the first question in Box one.

Source: CPC GHS time series datafile

Falling rates at younger ages resulted in an increasing prevalence of childlessness among women in their late twenties and above, as is shown in Table 1. For example, 41 per cent of women aged 25-29 in 1991-94 were childless, rising to 56.5 per cent by 2005/07; at ages 30-33 the figure rose from 24.8 per cent to 36.5 per cent ; at ages 26 and above, the rises in proportion childless over the period are statistically significant ${ }^{19}$. However, the growth in childlessness was accompanied by a growing intention among childless women to have at least one child, and there is no evidence of a move away from childbearing per se. As we saw in Figure 3, through the 1990s the proportion of women in their mid-20s and above stating that they did not want a (further) birth was either static or declining. This was true both for childless women of all ages, and for women aged 20 and over who already had children. In all, contemporaneous intentions information supports the widespread interpretation of recent trends as reflecting a continuous process of delaying rather than foregoing motherhood. Thus, birth intentions data appear to be helpful in interpreting current trends, a point to which we return.

\section{Table 1 Childless women by age, per cent, Great Britain 1991- 2007}

\begin{tabular}{lcccc}
\hline Age & $\mathbf{1 9 9 1 - 9 4} \mathbf{1 9}$ & $\mathbf{9 5 - 2 0 0 0 ~ 2}$ & $\mathbf{0 0 1 - 0 4}$ & $\mathbf{2 0 0 5 - 0 7}$ \\
\hline $18-21$ & 84.4 & 84.1 & 84.0 & 84.9 \\
$22-25$ & 64.0 & 68.3 & 69.5 & 67.4 \\
$26-29$ & 41.0 & 47.0 & 54.0 & 56.5 \\
$30-33$ & 24.8 & 30.5 & 37.7 & 36.5 \\
$34-37$ & 17.7 & 19.2 & 22.1 & 26.3 \\
$38-41$ 14.2 & & 14.8 & 17.0 & 18.3 \\
\hline
\end{tabular}

Note: cell sizes (unweighted) are in the range 650 to 2300 
The rising intention for at least one birth among childless women indicates that birth intentions data should be interpreted in their temporal context, and viewed against the backdrop of past aggregate trends. Where, as in recent decades, the schedule of childbearing has been shifting up the age range, women of parity zero at later time points in the process are a larger fraction of their age group and thus likely to be less select, in respect of both family size intentions and fecundity, than childless women of the same age at earlier phases of that temporal chang $\mathrm{e}^{20}$. Where, in the presence of such delay, there is little change in the ultimate intention to start childbearing, the outcome is a positive association between proportions childless and intention to have at least one further birth. This is seen in Figure 4, which plots, for four-year age groups 22-25 to 34-37, the proportion of childless women in each survey year who expected to have at least one birth (y axis) against the proportion childless at that age in the corresponding year ( $\mathrm{x}$ axis), during the period 1991-2005/07. At all ages these are directly associated, with correlation coefficients in the range 0.6 to 0.8 . The link is particularly strong from the late 20 s to the early $30 \mathrm{~s}$, the ages at which the greatest change in childlessness has been occurring. During this period, then, the proportion of parity zero women intending to have a birth is closely and directly linked with the proportion of the age cohort who are childless. The association is absent among younger childless women, and is less evident among parous women.

The net result of these offsetting movements is that the proportion of women at each age who either had, or expected to have, at least one child changed little over the period, as is seen in Table 2. In 1991-94 between 86 per cent and 89 per cent across age groups either had or expected to have at least one birth, and the range in 2005/07 was 84 per cent -91 per cent. There has, then, been no decline in the combined proportions actually having or intending to have at least one birth. Nevertheless, later childbearing means that a declining proportion have become mothers by a given age: for example, in 1991-94, 87 per cent of women aged 30-33 who had or intended to have at least one child had already had their first birth compared with 72 per cent in 2005/07; the figures are 95 per cent in 1991-94 and 86 per cent in 2005-07 for women aged 34-37. We examine in the next section how far expected and actual levels of progression to first birth coincide at the aggregate level.

\section{Intentions regarding first birth and its timing}

As noted earlier, the dominant influence on aggregate fertility in recent years is the progressively later age at childbearing. This is due largely to later ages at first birth rather than to a slower tempo of progression to higher order births. Between 1974 and 2007 the (age-standardised) mean age at childbearing rose in England and Wales by just over three and a half years, from 26.1 to 29.7. This is attributable entirely to later ages at first birth, the (age-standardised) mean age at first birth having risen by 3.5 years during the period, from 24.0 in 1974 to 27.5 in 2007 . Half of this delay took place between 1974 and 1991 (increase in mean age at first birth of 1.7 years), and half subsequent to 1991 (further increase of 1.8 years) ${ }^{21}$. We look here at how far intentional delay, or awareness of a likely delay, is evident in women's stated intentions.

Women who said that they would, or probably would, have a (further) birth were asked in the GHS interview to say at what age they expected to have their next birth. The answers to this question indicate that through the 1990s younger women without children were anticipating a growing delay in childbearing. Childless women aged 18-21 in 1991-92 declared that they expected to have their 
first birth 6.2 years later, and the figure had risen to 6.6 years by 2001-02 ${ }^{22}$. Among women 22-25, the anticipated wait rose from 4.5 to 4.9 years over the same period; at older ages, the increase is smaller, and in the mid to late 30s absent. The expected waiting time stopped rising in 2001/02 and eased very slightly after the turn of the century (Table 3 ). Thus, the waiting time estimated by younger childless women through the 1990s reflected the upward trend in the time to first birth.

\section{Figure 4 Percentage of childless women who intend to have a birth by proportion of the age group childless in each year, Great Britain1991-2005/07}

Age 22-25

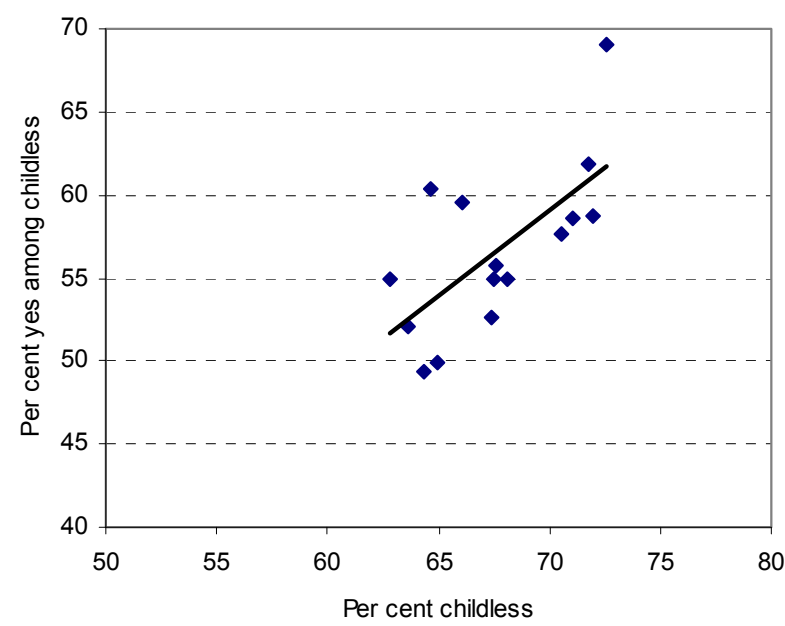

Age 30-33

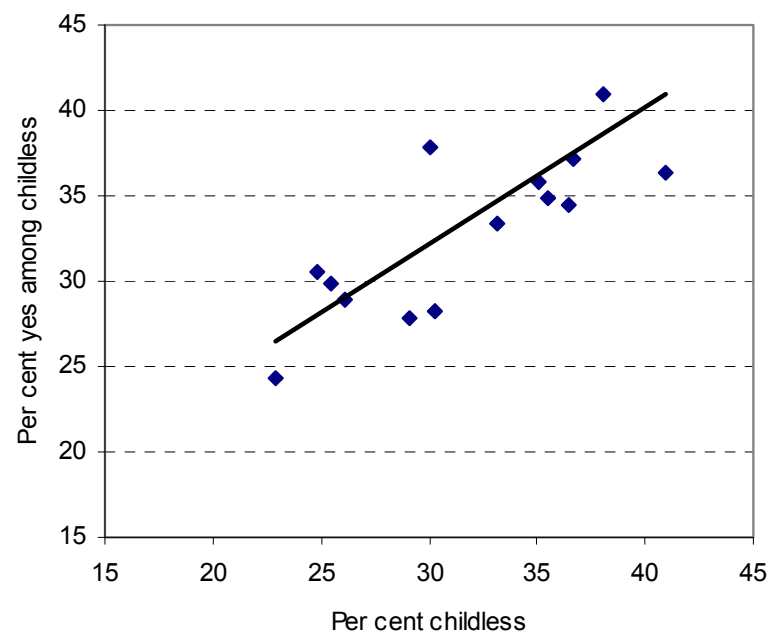

Age 26-29

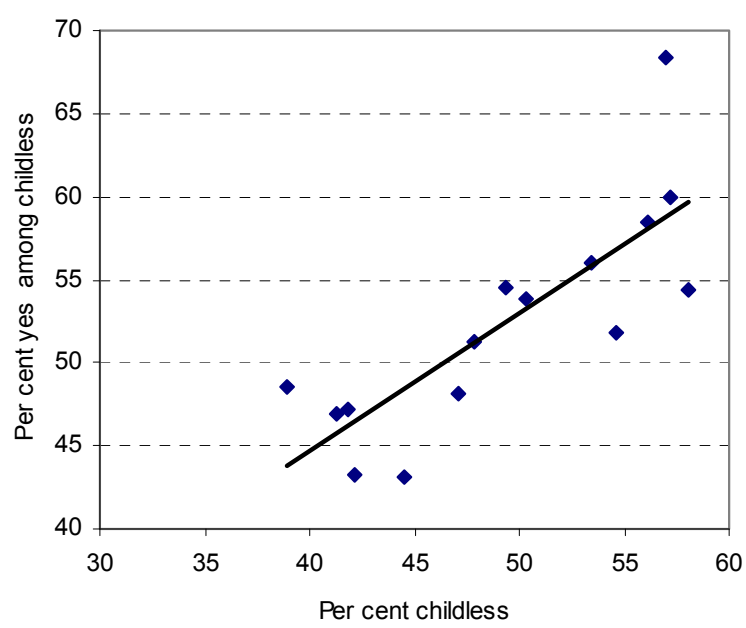

Age 34-37

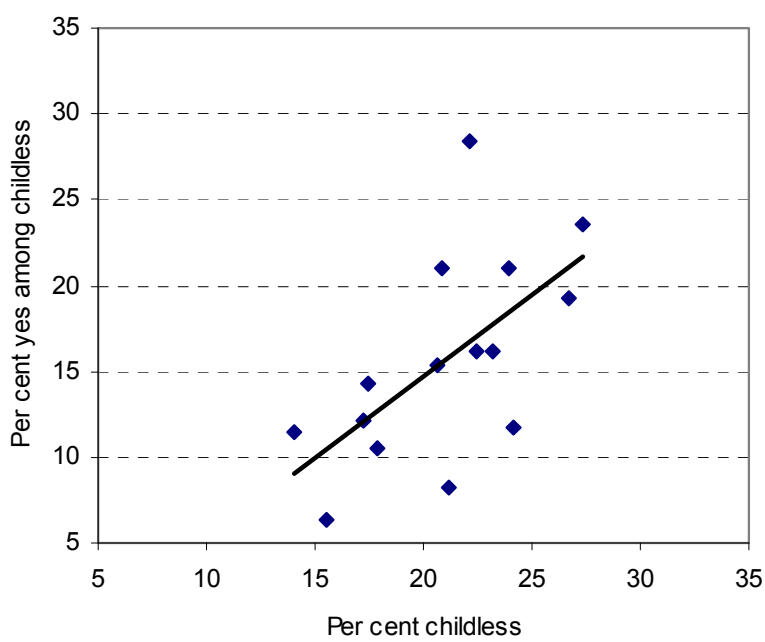

Source: CPC GHS time series datafile 


\section{Table 2a Percentage who have, or expect to have at least one live birth, Great Britain 1991-2005/07}

\begin{tabular}{lcccc}
\hline Age & $\mathbf{1 9 9 1 - 9 4}$ & $\mathbf{1 9 9 5 - 2 0 0 0}$ & $\mathbf{2 0 0 1 - 0 4}$ & $\mathbf{2 0 0 5 - 0 7}$ \\
\hline $18-21$ & 86.0 & 88.1 & 87.0 & 89.0 \\
$22-25$ & 89.0 & 88.8 & 88.1 & 90.9 \\
$26-29$ & 88.0 & 90.0 & 88.3 & 91.1 \\
$30-33$ & 86.9 & 89.7 & 87.4 & 88.6 \\
$34-37$ & 86.3 & 87.1 & 87.0 & 86.0 \\
$38-41$ & 86.4 & 86.9 & 85.4 & 84.0 \\
\hline
\end{tabular}

Note: the percentage tabulated is women who already have had or intend at least one birth.

\section{Table $2 \mathrm{~b}$ Percentage of those in Table 2a who have already had 1+ births, Great Britain 1991-2005/07}

\begin{tabular}{lcccc}
\hline Age & $\mathbf{1 9 9 1 - 9 4}$ & $\mathbf{1 9 9 5 - 2 0 0 0}$ & $\mathbf{2 0 0 1 - 0 4}$ & $\mathbf{2 0 0 5 - 0 7}$ \\
\hline $18-21$ & 18.1 & 18.0 & 18.4 & 17.0 \\
$22-25$ & 40.4 & 35.7 & 34.6 & 35.9 \\
$26-29$ & 67.0 & 58.9 & 52.1 & 47.7 \\
$30-33$ & 86.5 & 77.5 & 71.3 & 71.7 \\
$34-37$ & 95.4 & 92.8 & 89.5 & 85.7 \\
$38-41$ & 99.3 & 98.0 & 97.2 & 97.3 \\
\hline
\end{tabular}

Source: CPC GHS time series datafile

\section{Table 3 Mean duration in years before women expect to have their first birth. Childless women stating an expected age, Great Britain 1991/92-2005/07}

\begin{tabular}{lccccccc}
\hline Age & $\mathbf{1 9 9 1 - 9 2}$ & $\mathbf{1 9 9 3 - 9 4}$ & $\mathbf{1 9 9 5 - 9 6}$ & $\mathbf{1 9 9 7 - 2 0 0 0}$ & $\mathbf{2 0 0 1 - 0 2}$ & $\mathbf{2 0 0 3 - 0 4}$ & $\mathbf{2 0 0 5 - 0 7}$ \\
\hline $18-21$ & 6.2 & 6.3 & 6.4 & 6.4 & 6.6 & 6.5 & 6.4 \\
$22-25$ & 4.5 & 4.5 & 4.7 & 4.7 & 4.9 & 4.9 & 4.9 \\
$26-29$ & 3.3 & 3.4 & 3.7 & 3.5 & 3.6 & 3.4 & 3.4 \\
$30-33$ & 2.7 & 2.9 & 2.8 & 3.0 & 2.9 & 2.8 & 2.7 \\
$34-37$ & 2.1 & 1.9 & 1.9 & 2.0 & 2.1 & 2.0 & 2.2 \\
$38-41$ & 1.6 & 1.8 & 1.6 & 1.6 & 1.6 & 1.3 & 1.5 \\
\hline
\end{tabular}

Source: CPC GHS time series datafile

However, were their expectations accurate? We assess the accuracy of first birth expectations by comparing the stated intentions of childless women by age in 1991-94 regarding both whether and when they expected to have their first child against the actual fertility outcomes of a comparable sample of women ten years older identified from fertility histories collected ten years later in 2001$2004^{23}$. This comparison allows aggregate (net) accuracy to be evaluated.

The evidence suggests that women in the early 1990s were not particularly accurate in stating either whether or when they would have their first birth. Childless women on average overstate the likelihood of their having their first birth within a specified time. Three in ten childless women aged 18-21 in 1991-94 expected to have their first child within 5 years of the interview, and two in ten of that age group are estimated to have done so $^{24}$ (Table 4). Zero parity women in their early twenties and above overstate the likelihood of their having a first birth within 5 or 10 years by a 
larger margin. For example, while 55.6 per cent of childless women aged 22-25 in 1991-94 expected to have their first birth within 5 years, just 32.4 per cent had done so; comparable figures for women 26-29 are 61.8 per cent and 38.3 per cent. The gap between expected and actual proportions progressing to their first birth within 10 years is also substantial at all ages. If we regard all those who had a birth within 5 and 10 years of the initial date as having intended to have a first birth, we can make an approximate estimate of the fulfilment of the intentions of the childless by age in 1991-94. This ranges from just under half of childless women aged 34-37 who intended a birth within 5 years (12.9/26.3) to 84 per cent (42.9/50.2) of those aged 30-33 who intended a birth within 10 years actually having the birth within the expected time.

\section{Table 4 Percentage of childless women in 1991-94 expecting to have their first child within 5 and 10 years, compared with actual proportions proceeding within those durations estimated from fertility histories of 2001-04, by age in 1991-94, Great Britain}

\begin{tabular}{lcccc}
\hline \multirow{2}{*}{ Age } & \multicolumn{2}{c}{ Proceed within 5 years } & \multicolumn{2}{c}{ Proceed within 10 years } \\
\cline { 2 - 5 } & Expected & Actual & Expected & Actual \\
\hline $18-21$ & 29.9 & 20.5 & 76.5 & 45.5 \\
$22-25$ & 55.6 & 32.4 & 80.8 & 57.7 \\
$26-29$ & 61.8 & 38.3 & 70.6 & 56.8 \\
$30-33$ & 47.8 & 28.9 & 50.2 & 41.9 \\
$34-37$ & 26.2 & 12.9 & 26.4 & 17.5 \\
\hline
\end{tabular}

Source: CPC GHS time series datafile

The median times to first birth anticipated by women who expected to have their first birth within 10 years of interview in 1991-94, and a comparable figure for the actual outcome for equivalent women identified in the fertility histories collected at 2001-04 interviews, are given in Table 5. Women aged 18-21 specify the likely wait fairly accurately-an expected median of 5.7 years against an actual 5.5 years. Women in their early twenties and above in general anticipate an earlier first birth than actually occurs. These are, however, net figures and at the individual level, the correspondence between expectation and outcome will be less than this; also errors may compensate in different ways in different age groups, and so younger women may be individually no more accurate than are older women. Finally, the figures are conditional on the birth having occurred within 10 years, and as we saw, there is substantial inaccuracy in the aggregate concerning the proportions proceeding to a first birth within that time.

\section{Table 5 Expected and actual median time to first birth among childless non-pregnant women by age in 1991-94, Great Britain}

\begin{tabular}{lcc}
\hline Age & $\begin{array}{r}\text { Expected } \\
\text { (years) }\end{array}$ & $\begin{array}{c}\text { Actual } \\
\text { (years) }\end{array}$ \\
\hline $18-21$ & 5.7 & 5.5 \\
$22-25$ & 3.9 & 4.5 \\
$26-29$ & 2.6 & 3.7 \\
$30-33$ & 2.0 & 3.5 \\
$34-37$ & 1.4 & 2.8 \\
\hline
\end{tabular}

Actual medians derived from estimated fertility histories of 2001-04, by age in 1991-94.

Source: CPC GHS time series datafile 
The discrepancies both in the expected versus actual proportions proceeding to a first birth within five or 10 years show that starting a family is far from a precisely timetabled event in the life-cycle. This is evident also from the stated ages at first birth. Figure $\mathbf{5}$ shows the distribution of ages at which childless women of all ages in 1991-94 said they expected to have their first birth (period chosen for comparability with Tables 3-5). We see substantial heaping on ages ending in 0 and 5 , and to a lesser extent 2 and 8 . The distribution has all the classic features of digit preference in the reporting of age in demographic data sources by respondents who either do not know or are unsure of their age; digit preference is found in all periods in these data, as noted by Smallwood and Jefferies $(2003)^{13}$. Heaping in reports of the expected age at first birth is compelling evidence of substantial uncertainty as to both the eventual occurrence and the timing of the first birth.

\section{Life course}

We have seen both stability and change in fertility intentions across calendar time. We now examine how far fertility intentions change through the life course The GHS time series allows us to follow up birth cohorts across time periods, thus giving a succession of observations of intentions as cohorts age. As before, we are looking at aggregate change-in this case, the trajectory of cohorts rather than of individuals, and here too both stability and change are in evidence.

\section{Figure 5 Distribution of expected age at first birth, women of parity zero in1991-94, Great Britain}

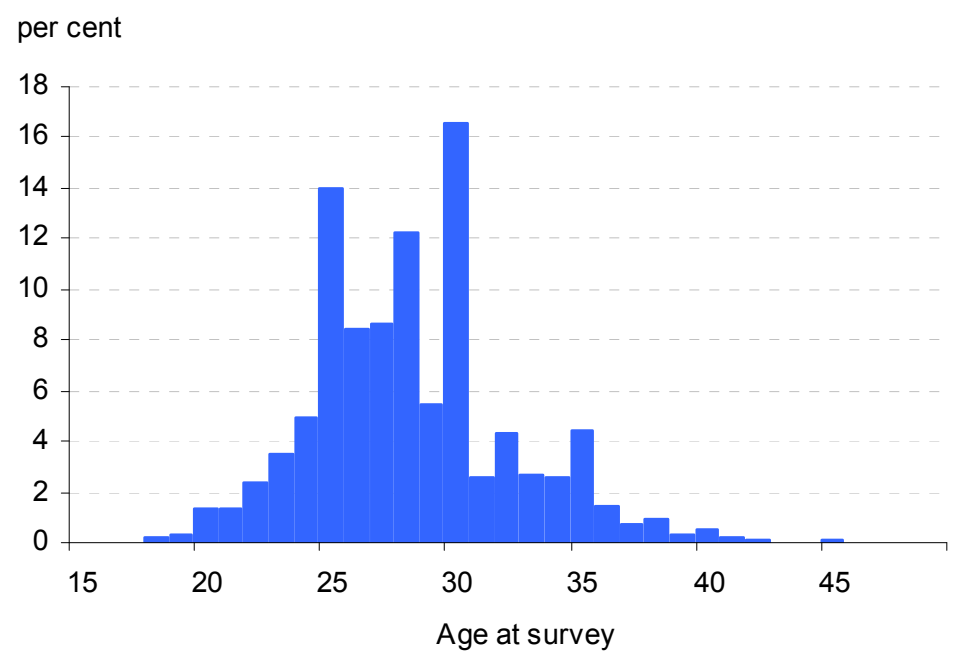

Among women born in 1968-71 and 1972-75, average intentions declined slightly with age. Intended family size averaged 2.1 children per woman at ages under 25 and registered a decline of 0.1-0.2 by the mid thirties. Much the same is found in other recent studies, though the extent of the reported decline across age is variable with time and place ${ }^{10} 25262728$. Change in intended mean family size with age is, of course, the result of change in the proportions intending, and ultimately having, specific family sizes. The shift in the distribution of intended family sizes is somewhat more substantial than suggested by the change in average intentions over the life course, in the cohorts considered. We see this from Figure 6 which summarizes the life course pattern of intra-cohort 
change in intentions for specific family sizes for women born in 1968-75. The picture is one of decline in the intention to have two children by age, especially when women reach their $30 \mathrm{~s}$, with a corresponding growth in an expected family size of zero or one. An estimated 53 per cent of women intended two children at age 18-21, and this had declined to 42 per cent by age 34-37; the eight per cent intending one child at ages 18-21 had, on the other hand, grown to 19 per cent by ages 34-37. The proportion intending three or more is relatively stable across age ${ }^{29}$. Note that while the focus here is largely on under-achievement of intended family sizes, some women may also have more children than originally intended. In the present aggregate analysis, however, the frequency with which women exceed intended family sizes cannot be determined.

\section{Figure 6 Percentage stating each intended family size by age,} cohort 1968-75, Great Britain

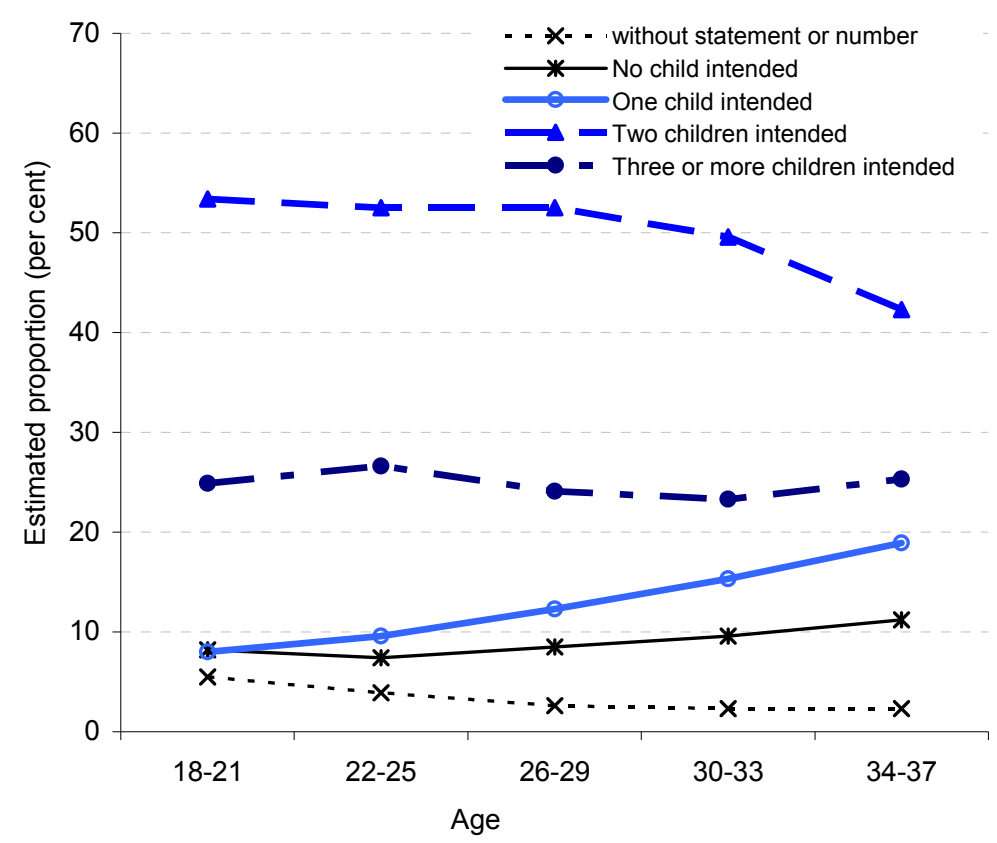

Source: CPC GHS time series datafile

Sample: Birth cohorts 1968-75

Intentions may of course, be unrealistic. In particular, according to stated intentions, 89 per cent of women aged 34-37 in this cohort expected to have at least one child, and thus just 11 per cent expected to be childless. In fact, just 75 per cent of this group had had their first birth at ages 3437. We can make a rough assessment of the proportion of these women who will eventually have at least one child. If we assume that the proportion who ultimately achieve a birth among those childless at age 34-37 and intending a birth is the same as the estimated 10 year progression from the aggregate 1991-94 to 2001-04 figures in Table 4 above-that is 66 per cent (17.5 per cent / 26.4 per cent) - that would give us an estimate of 16 per cent ultimately childless in this cohort, substantially above the intended 11 per cent, though somewhat below the ONS estimates of 19-20 per cent childless at 45 in the England and Wales cohorts of 1960 and $1963^{30}$.

One result of these shifts is that the variability of intentions grows with age within cohorts, as is seen in Figure 7. Women are more uniform in their family size intentions at younger ages but become more differentiated through the life course ${ }^{31}$. The numerical cause is the reduction by the 
late thirties in the two-child group and the increase in the one-child category, and to a lesser degree, those stating none. The gradual differentiation of women in their family building intentions as they age mirrors closely the same process in relation to achieved family size, whose variance also increases with age. Towards the end of the childbearing span, then, under recent conditions, women are more diverse in fertility outcomes than their expressions of intentions in their late teens and early twenties. Of course, intentions/expectations are necessarily close to the parity achieved by that age, and intentions at later ages are heavily constrained by the reality of declining fecundity as well as perceived risks, and possibly also normative sanctions stemming from the relative rarity in a low fertility society of childbearing at older ages.

\section{Figure 7 Standard deviation of intended number of births by age, birth cohorts 1964-67 to 1976-79, Great Britain 1991-2007}

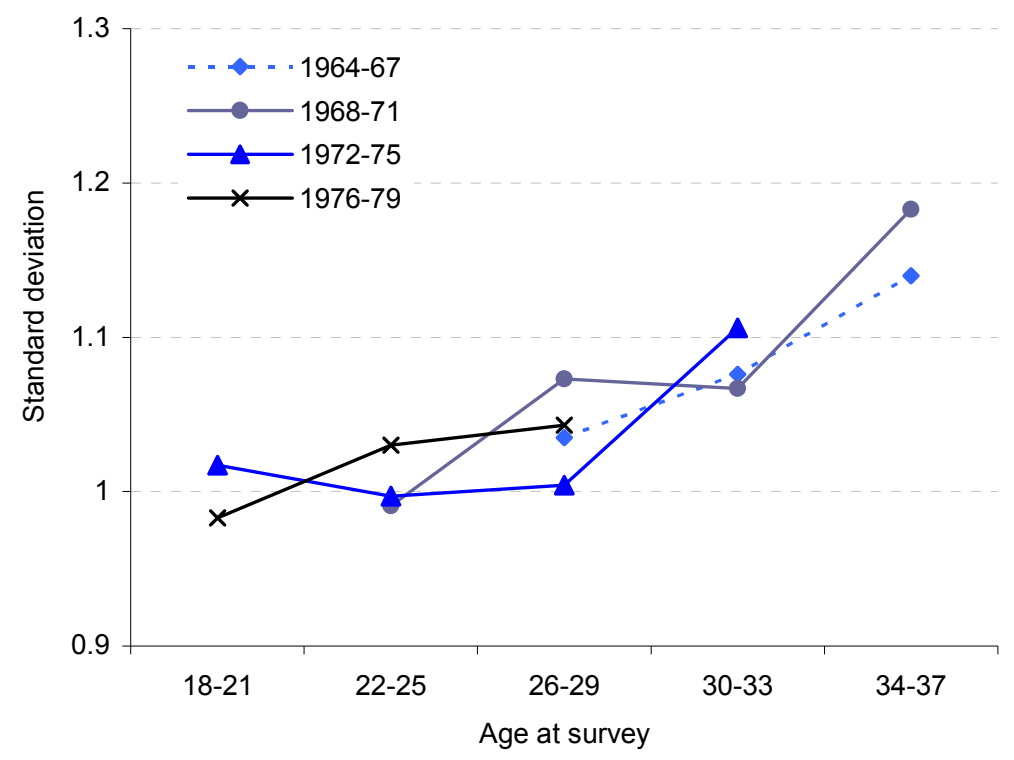

Source: CPC GHS time series datafile

\section{How certain are women about their fertility intentions?}

The question of what may be the origin of apparently shifting intentions across age raises the issue as to how clearly and certainly family building plans are formulated and held at various stages of the life course. It has long been recognised that fertility intentions are subject to considerable uncertainty, and that the inclusion or not of the fertility intentions of the uncertain can significantly affect estimates of mean intended family size ${ }^{32}$. Survey questions on the subject are variable, and the extent of uncertainty associated with fertility intentions varies correspondingly. Figure 8 shows the distribution by age of answers to the question whether women expected to have a (further) birth, in the GHS 2005-2007. From the base of the graph the answer categories are ordered as follows: no answer, don't know, probably yes, probably no, yes, and no (see also Box one). We combine the first four of these categories and classify them as uncertain. The no answer and don't know groups are a small fraction of those classified uncertain, as can be seen from Figure 8 . At ages up to the mid 30s just over three fifths of women give a definite answer on intention for a further birth, and that rises to nearly four fifths by their late 30s. Conversely, right up to the mid 30s, nearly four in ten women give an uncertain answer. The degree of uncertainty declared through the 
age range appears quite substantial, given that the question regards not a precise intended family size, but whether a (further) birth is expected.

We see also in Figure 8 that, as previous research has shown, uncertainty declines with age. But the GHS intentions data suggest that after age 30 this is primarily due to women who have already had at least two children. Uncertainty persists well into the thirties for women with fewer than two children. Figure 9 follows the cohort of women born between 1968 and 1975 through time, showing the proportions uncertain at successive ages, and so giving a picture of aggregate change through the life course, specific by parity. Among women with no children, uncertainty rises after age 30 with over half of childless women aged 34-37 being uncertain about their future childbearing. Among those with one child, uncertainty remains relatively high into the 30 s and begins to decline only in the late 30 s (Figure 9). However, uncertainty at the later stages of childbearing is by no means confined to women of below average parity. Among women in their late 30s who declared themselves uncertain about a (further) birth, four in ten had at least two children, a fifth had one child, and just over a third had no children; the childless were, thus, a minority among the uncertain. These data cannot tell us whether the elevated proportions uncertain among childless women in their 30 s reflects a selection process, or whether childlessness after 30 of itself gives rise to uncertainty. Another possibility is that it reflects a natural stage in the cycle of family formation ${ }^{33}$. But the level of uncertainty throughout the childbearing years, and its persistence into later ages, suggests that a significant minority of women do not make firm decisions about future childbearing. That a fifth of women at ages 38-41 give uncertain answers suggests a considerable degree of fluidity in orientation to fertility, well into the later years of childbearing.

\section{Figure 8 Distribution of intentions to have a (further) birth by age, Great Britain 2005-07}

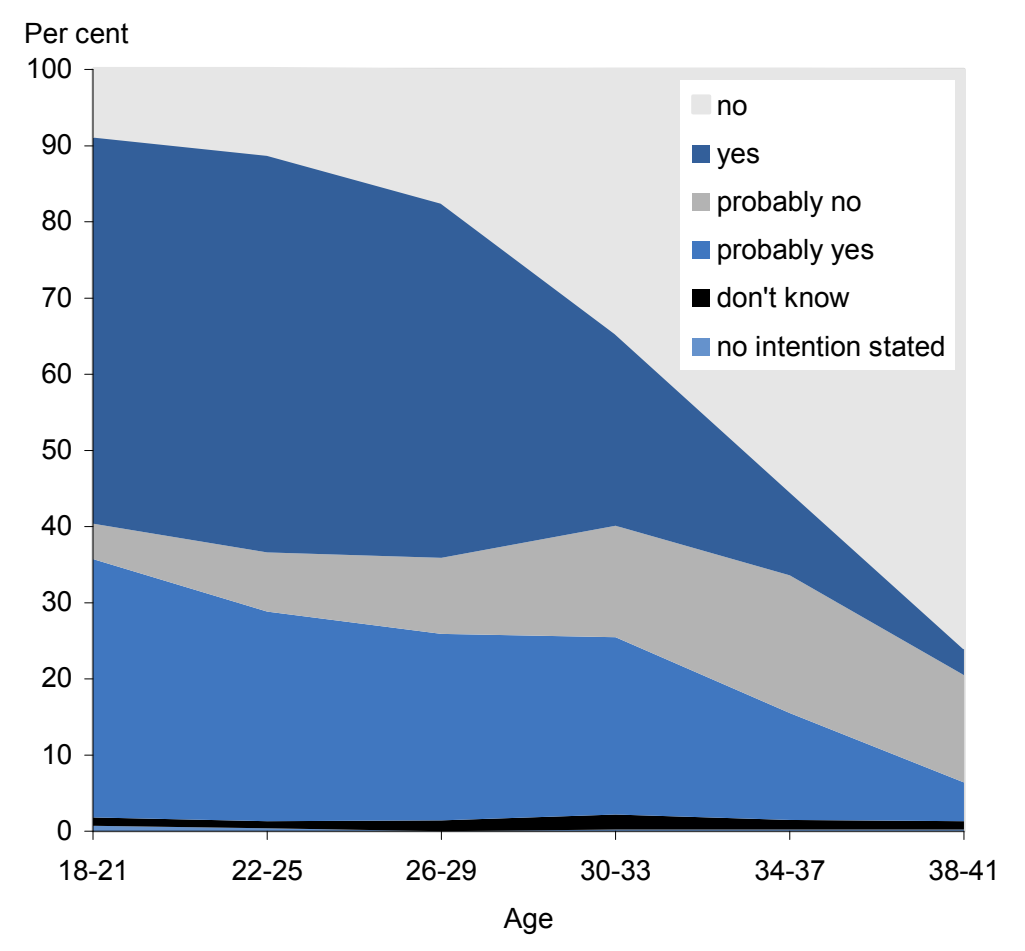




\section{Figure 9 Percentage uncertain in their fertility intention by parity and age, cohorts born 1968-1974, Great Britain}

\section{Proportion unstated, don't know or probably}

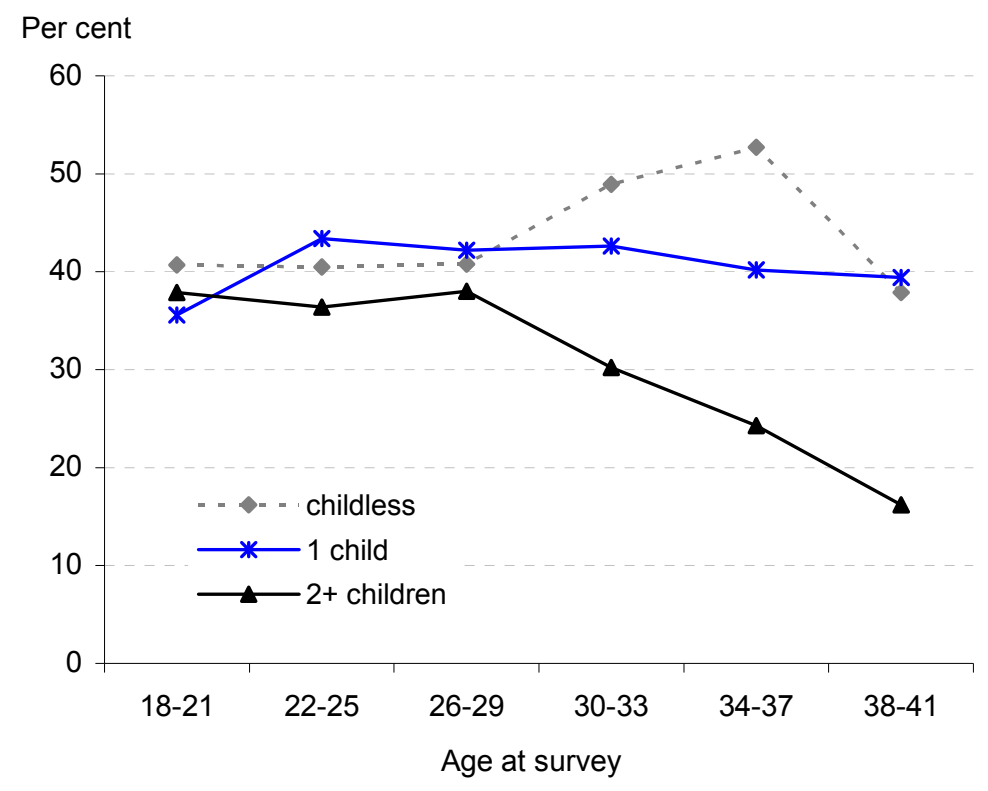

\section{Discussion}

Mean intended family size during the 1990s tracked overall fertility but did not anticipate the primary change point occurring at the turn of the century. This is much as would be expected from long-standing research showing that trends in aggregate mean intended family size tend either to lag or coincide with overall fertility trends. While average intentions may merely reflect how favourable current conditions are for childbearing, the present study suggests that data on intentions regarding the next birth may be more informative. They might potentially be used as an adjunct to conventional measures of overall fertility, an empirical alternative to tempo adjustment as a guide to the nature and implications of current aggregate fertility trends. However, to establish their validity for this purpose, longer runs of such data would be required, for a variety of temporal contexts, in periods of rising, falling, and static fertility, as well as of differing types of tempo change.

We have seen that women were, through the 1990s, anticipating a growing delay to motherhood, but that their expectations in that respect were inaccurate, in the aggregate, both in respect of the proportions ultimately achieving a first birth and in the timing of the first birth. The term 'postponement' in the context of fertility trends was used originally to refer to a short-term displacement of births in response to short-run conditions adverse to childbearing, such as depression or war, a decline in rates that is compensated by a later, and corresponding, rise ${ }^{34}$. The gap between expected and actual proportions progressing to a first birth, the underestimation of the average delay to first birth among childless women, strong digit preference in the expected age at first birth, and substantial uncertainty about future fertility, all suggest that postponement, in this short-term sense, is not the underlying process driving tempo change. Rather, the whole structure by age of incentives and opportunities for childbearing has been changing, resulting in a 
progressive shift up the age range in the fertility schedule ${ }^{12}$. The present data are, however, insufficient to fully illuminate the question as to the type and sequence of decisions that are being made through the life cycle in relation to the reproductive timetable. Large-scale longitudinal data at the individual level would be required to explore and document the behavioural mechanisms at work $^{12}$.

There has long been evidence of change across the life course in stated intentions regarding family size. Such change can be seen in different ways. On the one hand, we may view women and couples as having firm fertility intentions when young, and that these change with age due to learning, altered preferences associated with the experience of childbearing, competition with other activities, retrospective rationalisation, and a variety of constraints including fecundity, housing, economic factors, difficulties in partnership formation, partner preferences, as well as period influences ${ }^{27} 283536$. However, the level of uncertainty expressed both in the data analysed here and in other contemporary sources ${ }^{102637}$ suggests that many women do not have clear intentions regarding their future childbearing. Both preferences and intentions may be either ill-defined or unformulated for some women over a sizeable part of their reproductive life span, and even if certain of their wishes, their realisation may not be seen as within their control. Change in stated intentions has been found to be related to a variety of individual characteristics and circumstances. But the role of such factors need not necessarily be to modify preferences and intentions, but rather to make them more concrete. Thus, how far the shift in the distribution of intentions from younger to older ages represents true change, how far the crystallization of previously unclear preferences, and how far an adaptation to constraint, is an open question.

Insofar as definite childbearing preferences exist, one constraint on realising these may be establishing a suitable partnership. The presence of a partner is one of the strongest predictors of fulfilment of the intention to have a (further) birth, at the individual level 2628383940 . A recent European study found that having a supportive partner was perceived as second only to the mother's health as a circumstance relevant to the decision to have children, being mentioned by over seven in ten respondents. "Lack of right partner" was, in the same study, the leading reason given for having had fewer children than intended ${ }^{41}$. Just under half of childless women in their thirties in the 2005-07 GHS who were either uncertain about their birth expectations or expressed a definite "no", were not in a heterosexual union at the time of interview, compared with slightly over a quarter of those expressing a definite "yes". Partnership issues may thus be contributing both to the childlessness and to the uncertain expectations of this group (though reverse causation may also be at work). Uncertainty about partnership formation is thus a central reason why family formation may be perceived as not under individuals' control, and one potential source of the relatively high levels of uncertainty regarding fertility intentions found in the present study.

The implications at the aggregate level of the substantial uncertainty expressed at all ages are worth considering. Uncertainty pervades the stated intentions of women of all parities. While higher among those with fewer than two children, it features in the answers of a sizeable minority of women with at least two. Between a fifth and a third of women aged 22-37 with two or more children in the period covered by the present study gave uncertain answers on whether they will have a further birth. On this evidence, many women may be keeping their options open, and may be quite ready to react both to change in their personal circumstances and to aggregate period influences, whether favourable or unfavourable to childbearing ${ }^{33}$. 


\section{Key Findings}

- The gap between intended and observed fertility has narrowed since 2000. Mean intended family size during the 1990s tracked overall fertility, but at a level of about $0.3-0.4$ births per woman higher. Reported intentions did not anticipate the upturn in fertility that occurred around the turn of the century.

- Women were, through the 1990s, anticipating a growing delay to motherhood. But these expectations were inaccurate in the aggregate. Women overstate both the likelihood of their having a first birth, and how soon it will occur.

- Women give very approximate answers when asked when they expect to have their first birth, indicating that starting a family is not a very precisely planned event.

- Among recent cohorts, average intended family size declines somewhat with age. The proportion intending to have two children falls off with age, especially when women reach their 30 s, and correspondingly more, as they age, expect a family size of one child or none.

- The level of uncertainty in family building intentions and its persistence into later ages, among women of all family sizes, suggests that a significant minority of women do not make firm decisions about future childbearing.

\section{Acknowledgements}

This research is funded by ESRC Grant number RES-625-28-0001. The Centre for Population Change (CPC) is a joint initiative between the University of Southampton and a consortium of Scottish Universities in partnership with ONS and GROS. The findings, interpretations, and conclusions expressed in this article are entirely those of the authors and should not be attributed in any manner to ONS or GROS.

The General Household Survey is conducted by the Office for National Statistics. Access to the data is provided by the UK Data Archive.

The CPC GHS time series datafile was constructed with the assistance of Mark Lyons Amos. We thank the Office for National Statistics and the General Lifestyle Survey Branch for their help in clarifying various data issues.

\section{References}

1 See, for example, Demographic Research Special Collection 7: Childbearing Trends and Policies in Europe. Available at: www.demographic-research.org/special/7/

2 Frejka, T and Sobotka, T (2008) Overview Chapter 1: Fertility in Europe: Diverse, delayed and below replacement. Demographic Research 19: 15-46.

3 Goldstein, J R, Sobotka, T and Jasilioniene, A (2009) 'The end of "lowest-low" fertility?' Population and Development Review 35: 663-699. 
4 Tromans, N, Jefferies, J and Natamba, E (2009) 'Have women born outside the UK driven the rise in UK births since 2001?' Population Trends 136: 28-42.

5 Westoff, C and Ryder, N (1977) The predictive validity of reproductive intentions. Demography 14: $431-.453$.

6 Lee, RD (1980) 'Aiming at a moving target: Period fertility and changing reproductive goals.' Population Studies 34: 205-226.

7 Morgan, SP (2001) 'Should fertility intentions inform fertility forecasts?' Proceedings of US Census Bureau Conference "The direction of fertility in the United States". Washington, DC: US Census Bureau.

8 Goldstein, J, Lutz, W and Testa, MR (2003) 'The emergence of sub-replacement family size ideals in Europe.' Population Research and Policy Review 22: 479-496.

9 Hagewen, K and Morgan, SP (2005) 'Intended and ideal family size in the United States, 19702002'. Population and Development Review 31: 507-527.

10 Sobotka, T (2009) 'Sub-replacement fertility intentions in Austria'. European Journal of Population 25: 387-412.

11 See the special issue of the European Journal of Population, volume 25, no 4 on 'Fertility Intentions and Outcomes' edited by D Philipov (2009) and the current European Commission Seventh Framework funded 'Reproductive decision-making in a macro-micro perspective' (REPRO) cross-national study. Available at:www.oeaw.ac.at/vid/repro/

12 Ní Bhrolcháin, $M$ and Toulemon, $L$ (2005) 'Does postponement explain the trend to later childbearing in France?' Vienna Yearbook of Population Research 83-107.

13 Smallwood, S and Jefferies, J (2003) 'Family building intentions in England and Wales: trends, outcomes and interpretations.' Population Trends 112: 15-28.

14 So as not to duplicate cases we omit the first quarter of the GHS 2005 round from the 2005 dataset, as it consists of the final quarter of the 2004-05 survey round. A full year's sample was taken in the second, third and fourth quarters of 2005.

15 Murphy, M (2009) 'Where have all the children gone? Women's reports of more childlessness at older ages than when they were younger in a large-scale continuous household survey in Britain.' Population Studies 63 (2) 115-133.

16 Ní Bhrolcháin, M, Beaujouan, E and Murphy, M (forthcoming) 'Childlessness: a further look at cohort estimates based on survey time series data.' Paper to be presented at the European Population Conference, Vienna, 1-4 September 2010.

17 See for example, Casterline, JB and El Zeini, LO (2007) 'The estimation of unwanted fertility'. Demography 44: 729-745.

18 Confidence intervals for the estimated proportions intending at least one more birth at the start and end of the period are non-overlapping for childless women in age groups 26-29 and 34-37, when 2-year periods are used, and in all three age groups 26-29, 30-33 and 34-37 when 199194 is compared with 2005/07. Among women with children, the confidence intervals are nonoverlapping at ages 30 and over, whether 2-year or 4-year periods are used. 
19 These figures are based on our current best estimate of the parity of women aged under 40 in the GHS 1991-2005/07, which apply a substantial correction to the anomalies identified by Murphy (2009). However, work is in progress in evaluating these data further, and while our final estimates for these age groups may differ from those given here, any amendments are likely to be minor at ages under 40; at ages over $40+$, revisions may be more substantial.

20 The opposite would be true, however, of the later stages of a period of rising fertility, when the childless at any given age would be a more select group than at earlier stages. In general, past childbearing trends are likely to impact on the composition of any parity group with respect to intention, a feature that is additional to any aggregate change in intentions that may be occurring.

21 Figures for more recent years are given in Table 1.7b, Birth Statistics, Series FM1. Data for earlier years supplied by Fertility and Family Analysis Unit, ONS. Figures are ONS estimates of the age at "true" first birth, adjusting vital registration data for the order of births occurring within and outside marriage. The estimates are confined to England and Wales; they are not available for Great Britain. Age-standardisation removes the influence of the population age distribution. See Table 1.7b, Birth Statistics, Series FM1, available at: www.statistics.gov.uk/statbase/Product.asp?vlnk=5768

22 These figures relate to women who stated the age at which they expected to have their first birth. At ages under 26, the rise in expected delay between 1991-92 and 2001-02 is statistically significant.

23 The comparison made is a follow-up of age groups, rather than of individuals. It is carried out as follows, using as an illustration, those aged 18-21 in 1991-1994. The expected occurrence of and wait to first birth of non-pregnant childless women aged 18-21 in GHS rounds 1991-94 is compared with the actual time to first birth of women aged 28-31 interviewed in the 2001-2004 rounds, who, according to the fertility histories collected at 2001-2004, had their first birth within the 9 years and 5 months preceding their 2001-04 interview, or were still childless at 2001-04 interview. The comparison group at 2001-04 is thus defined retrospectively as childless and not pregnant 10 years previously i.e. women who were either of parity zero or a maximum of two months pregnant 10 years before their 2001-04 interview. This assumes that women who were up to two months pregnant would not have reported a pregnancy at interview. The comparison is constructed in this way as women who were pregnant at interview in 1991-94 were asked to state the age at which they thought they would have the next birth after the one they were expecting, and this, for pregnant women, would not have been their first birth.

24 Time to next/first birth is obtained as the difference between the stated expected age at next birth and age at interview. Age at next birth is an integer, and age at survey is, for the purpose, treated as age last birthday rather than exact age. A difference between the two of $<=5$ and $<=10$ are classified as within 5 and 10 years, respectively, and so assumes that the age at survey and stated next age are, on average, equal to the integer age plus 0.5 years.

25 Quesnel-Vallee, A and Morgan, SP (2003) 'Missing the target? Correspondence of fertility intentions and behaviour in the US.' Population Research and Policy Review 22: 497-525.

26 Berrington, A (2004) 'Perpetual postponers? Women's, men's and couples' fertility intentions and subsequent fertility behaviour.' Population Trends 117: 9-19.

27 Hayford, SR (2009) 'The evolution of fertility expectations over the life course.' Demography 46: 765-783. 
28 Liefbroer, AC (2009) 'Changes in family size intentions across young adulthood: A life course perspective.' European Journal of Population 25: 363-386.

29 Similar within-cohort patterns are evident in other sources, though details vary; see for example, Sobotka (2009) Figure 6, note 10.

30 ONS Birth Statistics 2008, Table 10.5. Available at:

www.statistics.gov.uk/statbase/Product.asp?vlnk=5768

31 This is consistent with recent findings for the Netherlands, and is reportedly true also of men. See Liefbroer (2009), note 28.

32 See for example, Morgan, PS (1981) 'Intention and uncertainty at later stages of childbearing: the United States 1965 and 1970.' Demography 18 (3) 267-285.

33 Morgan, PS (1982) 'Parity-specific intentions and uncertainty: the United States, 1970 to 1976.' Demography 19 (3) 215-334.

34 Hajnal, $\mathrm{J}(1947)$ 'The analysis of birth statistics in the light of the recent international recovery of the birth-rate.' Population Studies (1) 137-164.

35 Heiland, F, Prskawetz, A and Sanderson, WC (2009) 'Are individuals' desired family sizes stable? Evidence from West German panel data.' European Journal of Population 24: 129-156.

36 lacovou, M and Tavares, LP (2010) 'Yearning, learning and conceding: (some of) the reasons people change their childbearing intentions'. Institute for Social and Economic Research Working Paper 2010-22. University of Essex. Available at: www.iser.essex.ac.uk.

37 Kneale, D and Joshi, H (2008) 'Postponement and childlessness: evidence from two British cohorts.' Demographic Research 19: 1935-1968.

38 Schoen, R, Astone, NM, Kim, Y J, Nathanson, CA and Fields, J M (1999) 'Do fertility intentions affect fertility behaviour?' Journal of Marriage and the Family 61 (3) 790-799.

39 Testa, R and Toulemon, L (2006) 'Family formation in France: Individual preferences and subsequent outcomes.' Vienna Yearbook of Population Research: 41-75.

40 Morgan, SP and Rackin, H (2010) 'The correspondence between fertility intentions and behavior in the United States.' Population and Development Review 36 (1) 91-118.

41 Testa, R (2007) 'Childbearing preferences and family issues in Europe: evidence from Eurobarometer 2006 survey.' Vienna Yearbook of Population: 357-379. 